\title{
Applying Ethical Principles in Researching a Vulnerable Population: Homeless Women in Brisbane
}

\author{
Helena Menih*
}

\begin{abstract}
This article focuses on the ethics of doing ethnographic research within a vulnerable population, specifically homeless women. In this article I reflect on a number of ethical dilemmas that occurred during the fieldwork related to exclusion criteria, recruitment process, informed consent, the participant-researcher relationship and the researcher's safety. Through self-reflection I explore how applying ethical principles to researching a vulnerable population raises difficult questions. The aim of this article is to encourage further debate about the application of ethical principles when researching a vulnerable population.
\end{abstract}

\section{Introduction}

This article discusses the practical challenges of applying ethical principles while conducting ethnographic research about homeless women, although the same issues would arise in any criminological study concerned with street crime (see Putt 2013 in this Special Issue for a review of Australian research). The first section considers the growing international critical literature on the system of ethics regulation that developed in the US during the 1970s and has since been established in many countries, including Australia (Israel 2004; Oakes 2002; Westmarland 2011). Then a brief outline of the ethnographic approach employed in the current study will be presented. The next part will focus on the ethics application made before starting the fieldwork and the ethical principles that are relevant to doing research on homeless women. The focus of the article will be on the gap between how ethical concerns are considered by a university ethics committee and how these considerations are applied when conducting fieldwork. I will argue that, as an institution, the ethics committee marginalises vulnerable women and underestimates their abilities, while simultaneously attempting to protect them. The central question asked in this article is: How do we practically negotiate some of the ethical issues that rightly concern ethics committees when we are in the field and how does such regulation affect our research practice? The problems that arose in this project support the arguments made by ethnographers such as Jack Katz (2006) and Robert Dingwall (2008) that we need a more flexible process of ethics review that addresses and supports, rather than creates, obstacles and emotional difficulties for the ethnographer.

Helena Menih BA (Anthropology) MCCJHons is a doctoral scholar at School of Criminology and Criminal Justice, Griffith University, email: h.menih@griffith.edu.au. 


\section{Ethics and ethics committees: Some debates}

Qualitative methods are widely used by researchers to explore the viewpoints and experiences of disempowered groups and populations (Smith 2009). In recent times, social science research has become subject to extensive regulation, especially within universities (Monaghan et al 2013). The ethics system originated in the US as a response to some celebrated misconduct in medical, but also social scientific, research (Schrag 2011). It has also been established through legislation in other countries including Australia during the mid-1990s (Israel 2004). The system involves scrutiny of research projects by Human Research Ethics Committees ('HRECs') under the oversight of the National Health and Medical Research Council ('NHMRC'). Not only in Australia, but also internationally, it has become difficult obtaining permission from university ethics committees to conduct some forms of ethnographic research (Shaw 2003; Israel 2004).

The problems encountered by qualitative researchers have been reviewed extensively in many international books and papers. To give a few examples, Cloke et al (2000) explain the obligation that ethnographers have to ethics committees to provide them with solutions for ethical concerns that ultimately focus mainly on issues pertaining to the relationship between the researcher and research participants. The five sections of the National Statement for Research on Humans include: values and principles of ethical conduct; themes in research ethics (risk, benefit and consent); ethical considerations specific to research methods or fields; ethical considerations specific to participants; and process of research governance and ethics review (NHMRC 2007). Social science researchers using qualitative methods like ethnography need to carefully address all these points before conducting fieldwork (Israel 2004; Westmarland 2011). This means that researchers need to predict situations that might arise during fieldwork.

Israel (2004) explored interactions between Australian criminologists and HRECs at a time when there were many concerns among researchers. While for some the process was beneficial with constructive feedback, for the majority the process of negotiation was unsatisfactory and unduly constraining. A common complaint was that HRECs exaggerated the risks posed by criminological research. In addition, researchers were often asked to apply protocols (such as obtaining written consent) that were originally developed to protect patients in clinical trials, but were arguably not needed in social science projects (see also Hammersley 2010).

Monaghan et al (2013) further discuss problems relating to 'ethics creep', which seems to happen as committees extend their powers beyond a narrow definition of ethical conduct. An example is that they see the scientific merit of research as an ethical issue. Many studies have found that researchers can experience great anxiety and emotional difficulties attempting to obtain approval, and the review system has even resulted in projects being delayed or withdrawn. This has given rise to fierce criticism from some researchers. Schrag (2011:120) complains about 'silly restrictions'. Oakes (2002) sees HRECs as employing inappropriate standards derived from medical research. Dingwall (2008) even comments on the 'unethical' character of ethics review.

This short article cannot consider these criticisms in much detail. Some researchers have, for example, questioned whether the social scientific studies that are meant to justify controls were really harmful in the same way as medical experiments (Nicholls et al 2012). There are also critics who are more sympathetic to regulation (for example, Jennings 2012; Westmarland 2011), and suggest that ethics committees and researchers should work together to improve this process. What is not documented or discussed in much detail is how 
ethics review affects particular research projects. This article seeks to address a gap in the literature by examining how the ethical principles set out in documents such as the National Statement are realised in practice (see also Monaghan et al 2013).

\section{A study of homeless women in Brisbane}

Due to increasing female homelessness, in 2008 the Queensland Department of Housing, Families, Community Services and Indigenous Affairs published a White Paper in which two main aims were emphasised. The first was to halve homelessness by 2020 . The second was to offer supported accommodation to all 'rough sleepers'; that is, people without conventional accommodation who sleep on the streets, parks, dwellings or under bridges (Chamberlain and MacKenzie 2009). Little is known about homeless women's experiences, but the few studies that have been conducted suggest that women may be doubly disadvantaged on the street: first, for being homeless and, second, for stepping outside the traditional gender role. Thus, a more in-depth understanding of why women become homeless and how they cope with homelessness is required.

To achieve flexibility and reduce 'disturbance' to the research participants, ethnography was the selected methodological approach (Davies 2008). The reason for such exploratory research is due to the limited knowledge on this topic (Brewer 2000) - homeless women are considered to be a somewhat 'invisible' and hard-to-reach population and ethnography is a relevant and useful approach when researching vulnerable populations (Liamputton and Ezzy 2005; Martin and Kunnen 2008). So this research aimed to give these women voices. With participant-observation and life-history interviewing as the two main research methods, the key objectives of the research were to explore the interaction between the experiences of homelessness and the meaning attached to homelessness for women; to understand the coping mechanisms homeless women use on the streets; to explore what roles women play in the public and private spheres; and to explore reasons for and pathways into homelessness.

In order to conduct such ethnographic research, the approval of the university's HREC was required. Because of the nature of this research the HREC was required to consider many ethical issues before entering the field, including exclusion criteria, recruitment process, informed consent, the participants' wellbeing and the researcher's safety. All the ethical concerns that needed consideration were explored and addressed in detail. How some of these manifested in the field will be detailed next.

\section{The ethics application and the application of ethics}

In this section I consider each of the main ethical concerns that needed to be addressed and how each of these manifested in the field. They included exclusion criteria, recruitment process, informed consent, the participant-researcher relationship and the researcher's safety. Each was considered before the fieldwork began, but further questions arose once I was in the field. 


\section{Exclusion criteria}

There is some emphasis in ethics review on sampling, which may derive from the fact that ethics regulation first developed in the field of medical research (Oakes 2002; Schrag 2011). In this project, the ethics application asked for details as to who exactly would be the main participants in this research. I had to specify who would 'probably' be included and who would 'definitely' be excluded. I excluded two groups: participants had to be 18 or older; and they could not be highly dependent on medical care (through having a physical or mental disability). In these cases, special procedures are required to obtain informed consent (such as parental consent), and that might not be possible when researching people who are homeless. To satisfy this requirement, I gave an undertaking that I would take proactive measures to ensure that research participants' vulnerabilities were considered and addressed so that their participation would not result in harm.

Additionally, the application addressed each of the special circumstances of the groups that needed ethical consideration in detail. It explained that while I would probably come across the majority of these groups (people whose primary language is other than English, women who are pregnant, people with a cognitive impairment, and intellectual disability or a mental illness, Aboriginal and/or Torres Strait Islander peoples and people who may be involved in illegal activity), most would not be included/recruited for life-history interviewing. This is because some of the women from certain groups might have completely different needs and experiences to others.

In the field I came across all of these groups, including those I excluded in the ethics application. This research was conducted in public spaces (such as parks, streets, services and so on), so I could not control the environment or who was in that environment. Therefore, once I started an informal conversation, I could not ask participants whether they were involved in illegal activity. This is quite a personal question that one does not ask in a first encounter. As a result, it was very hard to establish the exact 'group' to which a certain participant would belong for the purposes of the ethics application.

For example, one day I spent a few hours in the park with a group of homeless people (men and women). One of the homeless women took me there to sit with the group and observe their daily routine. As soon as we got there, they pulled out a bottle of alcohol and poured it into plastic bottles, so they could disguise their drinking. Although I was aware their actions were illegal, I could not really say anything as I wanted to observe their daily activity. Hamm and Ferrell (1998) have indicated criminologists tend to go to spaces that can be somewhat uncomfortable and, as Marks (2012) emphasises, sometimes there are no easy answers to questions that might arise, especially questions relevant to what is ethical or unethical.

\section{Recruitment process}

For the ethics review process I needed to explain the recruitment process in some detail. I explained that participants would be recruited using a non-probability method, meaning that they would possess the attributes I wanted to study. Over a few months of non-invasive overt observations of women experiencing homelessness I would assess who would be the potential participants for life-history interviewing. At the completion of participant observation I would approach a potential participant while she was in a public space. I would introduce myself, explain that I was a researcher and advise her of the nature and aims of my research. I would explain what the participation entailed and some of the potential risks and benefits. I would explain what measures would be taken to ensure the confidentiality of the information she would provide. I would also supply the participant 
with an information sheet and ask for her signature on the consent form. Potential interviewees would also be advised that participation in this research project was voluntary, so they could withdraw at any time. I would then ask them to give their life story in an extended interview for a few hours each day over the next few days.

Throughout the fieldwork, this recruitment process raised difficult issues (Chaing et al 2001), and invariably it was necessary to modify the procedures described in the ethics application. For example, in one situation I approached a woman per the established informed consent process. Then, once she agreed to the interview and I gave her the information sheet to read and informed consent form to sign, she insisted on signing the information sheet without reading it. I wanted to read aloud the various paragraphs, but she insisted there was no need and that we should proceed to the interview. This situation made me a bit uncomfortable as I felt I needed to stick to the rules, even if I might lose a participant.

A similar situation occurred a few weeks later when I was just 'hanging around' at one of the service providers' and a worker approached me and said there was a woman in his office who might be interested in participating. One of the first things I did when I entered the room was introduce myself and my study. I then proceeded to explain the information sheet and informed consent procedure. She pointed out that she could not read, so I said I would read the information sheet to her before she signed the consent form. After reading aloud the second paragraph on the information sheet she indicated that she wanted to sign the consent form and that I did not have to continue. In order to satisfy the ethics requirement and to keep my participant from leaving, I read the first sentence from each of the sections. I think this was more for me than for the participant. Both of these situations show that, no matter how well structured my recruitment process might have been, I tended to improvise when I was recruiting women for the interviewing stage. Such improvisations left me feeling uncertain whether I had complied with the procedures set out in the ethics application, but there seemed no way to comply without adapting the procedures.

Cloke et al (2000) emphasise the difficulty of considering all the ethical dilemmas that might occur during a fieldwork project before the research begins. The majority of ethical predicaments arise situationally and have to be managed in the field. They cannot be addressed by general statements or principles of ethical conduct. De Laine (2000:3) stated that, during fieldwork, 'researchers experience ethical dilemmas with an immediacy and personal involvement that draws on intuition and empathy, feelings and emotion'. Thus, diverse circumstances require various adaptations during the fieldwork. Hay (1998) argues that, because of this, the formal systems that govern ethnographic research should become more flexible.

\section{Informed consent}

Informed consent is one of the main requirements for researching human subjects (Wax 1980; Marks 2012). The ethics committee overseeing my application required an explanation of the approach to be taken when obtaining informed consent from specific groups. I explained that the selection of research participants for interviewing would commence during the participant-observation phase. I would approach women in order to gain their consent to give a life-history interview while engaging them in conversation. This means that, even before I had obtained consent, I would already be more than a detached observer.

Further, even though I ticked boxes on the ethics application form identifying particular groups to be included or excluded from the research project, it quickly became clear that 
homeless women are not a homogeneous group. In each individual, there is often an intermixture of race, class, age, sexuality, mental illness, and substance abuse. One category that is viewed as highly important by ethics committees is the age of participants. In this project, I promised that none of the participants would be aged less than 18 years. If I identified women suffering from substance abuse, I would attempt to engage them in conversation when they still had the ability to provide informed consent, which would be prior to their use of substances. If I encountered women who displayed signs of mental illness, I would seek advice from my gatekeepers and/or use my discretion when deciding their capacity to give informed consent.

In the actual field, I had to improvise a great deal in regard to informed consent. This was mainly because meeting homeless women for the first time made it hard for me to determine their age or whether they had mental health issues. One time I was in the field having an informal conversation with a young woman. I was a bit reluctant to ask her to disclose her age straight away, so I approached a worker or a volunteer in order to learn the age of this participant. Another improvisation was when I was trying to gain informed consent from a woman who was willing to sign a form and participate in the study but appeared to be under the influence of drugs. This occurred in the evening so I decided to wait until the next day. I could not find her for a few weeks and by the time I came across this woman again she had forgotten about my research. Further, she changed her mind regarding participating in an interview. I felt disappointed over losing an interview, while respecting her right to give consent or withdraw from the project. Nevertheless, this indicates the difficulties of knowing whether someone can give consent. It is not as clear as the procedures described in ethics applications.

Miller and Boulton (2007) discuss the socially constructed nature of informed consent, emphasising the fluid social world and regulated ethics procedures. They suggest there is trust on the part of ethics committees in researchers' abilities to make certain decisions in the field, especially when dealing with issues related to informed consent. Murphy and Dingwall (2007) relate the process of informed consent to flexibility of the ethics process, stating that, even with the information provided by the researcher, the participant might not be aware of any other emerging issues when sharing personal information. More specifically, in criminological research, participants might be reluctant to sign the consent due to fear of exposure (Marks 2012) or fear of deceit (Van den Hoonaard 2001).

\section{Participant-researcher relationship}

In the ethics application I had to explain the role I intended to play in the field. Spradley (1980) discussed the roles a researcher takes when employing participant-observation as a method. The relevant role for me would be that of a detached observer and 'moderate' participant (according to Spradley 1980). This means that I would maintain a balance between being an insider of the observed group and being an outsider. This balance would be of great importance. In order for me to obtain the required data I would need to form relationships with the participants. However, I was not supposed to get involved in or influence their lives in any way.

From my first day in the field I made an effort to be a detached observer. This was possible in the first few days. However, later, when I needed to engage in a conversation with participants, I became a participant. A lot of people expressed interest in my presence around different service providers. For the first month I was a detached observer and only observed homeless people. The only people I had conversations with were the workers at different service providers. As the days passed, I shortened the distance from my usual 
'observing space' to a closer distance: I wanted to observe and hear the conversations at a closer proximity. I did this via sitting in the waiting area at the facilities of various services, sitting in the smoking area outside these facilities and attending different activities. Even when I was closer to homeless people at this point and overheard their conversations, I continued to maintain my detached observer position. However, somewhere halfway through the second month of my fieldwork I became a moderate participant. This occurred mainly because homeless people started inquiring about my presence.

I was well aware that I needed to keep my participation to a minimum and still try to engage in informal conversation as much as possible. This was also the reason why I did not want to present myself as a volunteer or a student worker (due to their misconception of my presence). I was clear from the beginning that I was a researcher doing this research and I was just there to observe and talk to homeless women. This was quite well accepted and they were aware not to expect any advice or help from me regarding their situation. Sometimes, even if I knew the answers to some of their questions, I tried not to provide any answers. I did not want to confuse my role as researcher with that of worker/volunteer. At times I felt useless. I was too concerned with the requirements of my role and, although this kept me at a moderate participation stage, I wanted to be more active. This internal struggle was so strong that sometimes I discussed my observations of these homeless women with the workers. Does this mean I behaved unethically?

As the time passed and relationships formed, I maintained my role as a moderate participant. At many times some of the homeless women expected more from me, mainly in the context of emotional support. For example, one night when I was at the facilities where they hold 'Crash nights for women only' there was a clash between two women and one of them got very upset. She ended up running into one of the spaces in the facility and crying. I wanted to know what the argument was about, and entered that room with one of the volunteers. When the volunteer was asking the homeless woman about the argument she continued to cry and then said, 'Can you hug me?', and before I could even answer she already had her arms around me. As a result, I was no longer an outsider, but suddenly an insider. After the hug I moved to the other corner of the room, so I was further away from her and the volunteer, stepping back into an outsider role. Here again I felt torn between being a participant and maintaining the detached stance required by the ethics committee.

Throughout my observations I discovered that for homeless women a lot of situations could get very emotional and at times they expected some emotional support from the people next to them. Since I did not want to form relationships that were based on emotional closeness, I physically and verbally removed myself from such situations. I was very conscious that establishing such relationships could become a barrier to collecting research data. My observations could have become incomplete (Davies 2008). Nevertheless, giving support could lead to greater trust. At all times, I was careful to take appropriate steps to make sure participants knew what my place in their lives was - detached observer and moderate participant.

In the field, many questions were raised and, while some of these issues were addressed in the section of the ethics review where participants' wellbeing needed to be addressed, as Israel (2004) points out, there are other issues criminologists need to negotiate when conducting qualitative research. Hammersley and Atkinson (2007) describe the researcher's responsibility to avoid negative consequences that could harm the researched group in any way. Participants' physical or emotional wellbeing is further emphasised through the ethics process. Research with human subjects should be guided by principles such as respect, 
justice and beneficence (Sieber 1982). While these values guide a researcher, there are still many situations in the social world that require improvisation and compromise.

In the ethics application, I was required to address issues such as the emotional and psychological impacts my project might have on participants. I have pointed out that throughout the participant observation phase my role would be moderate, which means that, as an observer, I would not become a participant in the daily activities of the women being observed. I would make clear that, in case of any distress or harm homeless women might experience, they would be directed to free counselling services where they could seek help. Further, if I observed that a participant was having difficulties, I would seek advice from one of these counselling services. In the beginning of the interview I would also provide details about all the help available from different service providers.

When interviewing, I quickly learned that most of the women were already aware of these services and never really wanted to use them. I also noticed that some participants felt the need to use counselling services because I suggested this during the interview. I quite disliked this because it gave me a feeling of predetermining the way the interview might go, as well as encouraging the use of a service that may not always be appropriate or effective in assisting this vulnerable group. Perhaps other forms of intensive support, rather than counselling, might work better with such populations.

This became evident after one of my interviews. The interviewee told me that she never used any of the counselling services, but talking to me gave her some sort of relief. She agreed to another interview session because of this. This raises questions about my role in the field. Should participants see me as a counsellor or as a researcher? The aim of the research was to learn women's life stories, but, at the same time, I wanted to provide comfort and ease the difficulties of their lives. Was this ethical, and how should I negotiate my role here?

The emotional wellbeing of these women is important, yet I learned that these women tended to be much tougher than the standard ethics application assumes in requiring the researcher to offer counselling. The ethics system assumes such support must always be beneficial, especially for a vulnerable population. Consequently, the ethical considerations seemed very paternalistic in regard to protecting marginalised populations.

Another setting where I questioned my role occurred when a woman I was talking to broke down in tears. This happened because her homeless situation was particularly 'fresh' and sensitive. Since I wanted to maintain my distance as an observer, I directed her to one of the service workers instead of trying to comfort her. I felt extremely uncomfortable doing this. She opened up to me and, rather than trying to calm her down, I passed her on to someone else. So, what would be the right thing to do? What did the (perceived) lack of empathy from me mean to this participant for further participation? Addressing the wellbeing of participants who are considered vulnerable is particularly important. Yet, when forming relationships in the field, the line between what a researcher should do and needs to do can be blurred. I felt that I should have stayed with her. I felt torn here - on one hand, there was a moral obligation towards the participant and, on the other, there was my ethical responsibility. How should I negotiate my role in these situations?

In criminological research the questions of obligations of beneficence and nonmaleficence are raised at a general level (Israel 2004). They are particularly relevant when the research is concerned with a vulnerable population. Here, interpersonal relationships need to be considered; in particular, relevance to participants' and researchers' wellbeing (Israel 2004). Katz (1999) and Murphy and Dingwall (2007) discuss emotions in the field, 
pointing out there are some complex emotional states that can arise during fieldwork, such as anger or disappointment. My own experience demonstrates how the ethics codes can themselves contribute to these emotional difficulties since, as a researcher, I was often unsure about whether I was behaving ethically, or how to apply or interpret the HREC's principles.

\section{Researcher's safety}

Even though there have been many debates about how to protect research subjects, there has been less recognition of the difficulties that arise in attempting to protect the researcher from harm (Downey et al 2007). The ethics committee was concerned about my safety. However, the measures used to protect me created problems in conducting fieldwork and affected my sense of wellbeing.

Pickering (2003) explains that, in her research with minorities, trust was an important issue. Thus, before conducting interviews, a certain period was spent in participant observation in order to gain the trust of a researched minority. Most often, to gain trust a researcher needs to 'act' according to what is 'normal' in terms of the researched population. Since this is an under-researched area and the understanding of homeless women's lives is lacking grounded information, I decided to employ a different approach to gain their trust. I sought to use as my gatekeepers various agencies/organisations that the homeless women were accessing.

Further, there was an issue of my safety in this public space. I had to ensure my safety when I spent my days in the field. To address this problem, I obtained guidance from Chih Lin (2003), who conducted research in a prison. She interviewed male prisoners in the same way prison staff did. This placed her in danger. However, she experienced exactly the same risk prison staff ran daily. In her opinion, this expressed her trust in the prisoners and, in return, the prisoners trusted her. My own approach to researching homeless women was similar. I exposed myself to the same dangers as experienced by anyone in this area of Brisbane. However, I still took some safety precautions. During the initial stage of fieldwork, I was never alone. I was always accompanied by one of my gatekeepers - either a case worker, a staff member or a volunteer.

In the field I noticed that the majority of homeless women entirely trusted people working at the agencies where I was conducting my observations. They talked to me freely without concerns about why I was conducting the study or how I might use the data. On the other hand, some women looked at these agencies/services as authorities or in a negative way, and did not trust me. For example, one woman recently went through a custody battle with her abusive ex-partner. On the day I was scheduled to conduct an interview with her, she learned that her ex-partner received full custody of their daughter. She came to me and said: 'I do not want to talk to the government!' I tried to explain what my role was, but her mind was set.

This indicates the essential role of gatekeepers, which was also a limitation when approaching some women. The gatekeepers ensured my safety in the field. However, being associated with them also made my fieldwork less fluid and flexible. I had to adjust my time in the field according to gatekeepers' work schedules and work methods. In addition, my research in the 'actual' public space was very limited because of this safety issue. A lot of participants associated me with my gatekeepers. At times I was asked questions that related to social work and, even though I regularly pointed out that I am a researcher, this kept happening. However, what would have happened had I not used gatekeepers? Could my 
research have become more covert than overt? How should I manage the role of researcher and the relationships between gatekeepers and participants?

Another safety issue I needed to address in the ethics application was related to 'fitting in' with the researched population. Pickering (2003) and Garcia-Johnson (2003) both emphasised the importance of 'blending in' in order to feel safe in the field. That can either mean changing your appearance or living in the same area as the participants. In order to 'blend in' and gain trust, I aimed to change my appearance so that I would be wearing clothing that was not too noticeable. Still, according to the advice I received from the ethics committee, I needed to distinguish myself from participants. The committee suggested that I should wear a name tag, thus separating myself from my gatekeepers and the participants.

In the field, the name tag created extensive curiosity about its meaning. The participants first saw the name tag and then asked questions about my presence. This resulted in my role as a researcher being exposed too soon. I was not able to 'blend in' and observe from a distance. So, did the name tag compromise my role as a researcher and, in turn, endanger my safety, or did this distinction ensure my safety? It made me feel uncomfortable on some occasions while in the field. For example, one day I was in a park with one of the homeless women. While I was chatting with her, some of her friends who were also homeless approached us. After realising I had a name tag, they all seemed more interested in who I was than in joining us in conversation. This resulted in too much focus on me instead of the research participants.

Dangerous situations are part of criminological research (Lee 1995). Israel (2004) indicates that some researchers need to spend a certain amount of time learning about the research site and the people within - and what dangers can arise in the field. As participants in this study are considered vulnerable, under-researched and to have complex needs, it was hard to predict some of the dangers. Thus the ethics guidelines 'overprotected' the researcher and, as Martin and Dingwall (2007) have shown, this can affect the quality of data collected within a public space.

\section{Conclusion}

This article has discussed ethical concerns - such as exclusion criteria, the recruitment process, informed consent, the participant-researcher relationship and the researcher's safety - that are considered by ethics committees. Each of these was explored in regard to the requirements made by the university's ethics committee that approved my ethics application, but also by looking at the effects of these requirements when conducting fieldwork with a vulnerable population. Throughout my fieldwork, difficult questions were raised and no answers were offered by the formal documents. As a result, I experienced uncertainty about my role as a researcher. Strauss and Corbin (1998) emphasised that the researcher in the field always has to improvise when collecting research data. This also happens when trying to behave ethically following general principles. It is always necessary to make compromises and this creates for the researcher emotional difficulties that are arguably unavoidable when conducting ethnographic research (Hammersley and Atkinson 2007).

Further, in my experience it became clear that ethics committees tend to marginalise vulnerable women and underestimate their own abilities while simultaneously attempting to protect them. Such a paternalistic approach limited me as a researcher in some situations. It left many questions unanswered and, like the doctoral researcher whose experiences are 
reported by Monaghan et al (2013), it left me doubting my moral values and my responsibility as a researcher to the researched population and to the appropriate government agencies (such as the ethics committee). This is not intended to suggest that ethics regulation has no value, or cannot be improved (Westmarland 2011) by recognising some of these shortcomings. What it does suggest is that more happens in an ethnographic research project than can be governed or managed by the general principles found in ethics codes.

\section{References}

Brewer D (2000) Ethnography, Open University Press, 2000

Chamberlain C and MacKenzie D (2009) Counting the Homeless 2006: Queensland, Cat No HOU 205 (9 July 2009) Australian Institute of Health and Welfare <http://www.aihw.gov.au/publicationdetail/?id=6442468260>

Chiang CV, Keatinge D and Williams KA (2001) 'Challenges of Recruiting a Vulnerable Population in a Grounded Theory Study', Nursing and Health Sciences 3, 205-11

Chih Lin A (2003) 'Going to Prison' in Feldman MS, Bell J and Berger MT (eds) Gaining Access: A Practical and Theoretical Guide for Qualitative Researchers, AltaMira Press, 2003

Cloke P, Cooke P, Cursons J, Milbourne P and Widdowfield R (2000) 'Ethics, Reflexivity and Research: Encounters with Homeless People', Ethics, Place and Environment 3(2), 133-54

Davies CA (2008) Reflexive Ethnography: A Guide to Researching Selves and Others Routledge, $2^{\text {nd }} \mathrm{ed}, 2008$

De Laine M (2000) Fieldwork, Participation and Practice: Ethics and Dilemmas in Qualitative Research, Sage, 2000

Dingwall R (2006) 'Confronting the Anti-democrates: The Unethical Nature of Ethical Regulation in Social Science', Medical Sociology Online 1, 51-8

Dingwall R (2008) 'The Ethical Case against Ethical Regulation in Humanities and Social Science Research', Twenty-First Century Society: Journal of the Academy of Social Sciences 3(1), 1-12

Downey H, Hamilton K and Catterall M (2007) 'Researching Vulnerability: What about the Researcher?', European Journal of Marketing 41(7/8), 734-39

FaHCSIA (2008) The Road Home: A National Approach to Reducing Homelessness, Department of Families, Housing, Community Services and Indigenous Affairs $<$ http://www.fahcsia.gov.au/sites/default/files/documents/05_2012/the_road_home.pdfs

Garcia-Johnson R (2003) 'Accessing Business, Government, and Nongovernmental Organization Actors in Mexico and Brazil' in Feldman MS, Bell J and Berger MT (eds) Gaining Access: A Practical and Theoretical Guide for Qualitative Researchers, AltaMira Press, 2003

Hamm M and Ferrell J (1998) 'Confessions of Danger and Humanity' in Ferrell J and Hamm M (eds) Ethnography at the Edge, Northern University Press, 1998

Hammersley M (2010) 'Creeping Ethical Regulation and the Strangling of Research', Sociological Research Online 15(4), 16

Hammersley M and Atkinson P (2007) Ethnography: Principles in Practice, Routledge, $3^{\text {rd }}$ ed, 2007 
Hay I (1998) 'Making Moral Imaginations. Research Ethics, Pedagogy and Professional Human Geography', Ethics, Place and Environment 1, 55-76

Israel M (2004) Ethics and the Governance of Criminological Research in Australia, New South Wales Bureau of Crime Statistics and Research <http://www.bocsar.nsw.gov.au /lawlink/bocsar/11_bocsar.nsf/vwFiles/R55.pdf/\$file/R55.pdf>

Jennings S (2012) 'Response to Schrag: What are Ethics Committees for Anyway? A Defence of Social Science Research Ethics Review', Research Ethics 8(2), 87-96

Katz J (1999) How Emotions Work, University of Chicago Press, 1999

Katz J (2006) 'Ethical Escape Routes for Underground Ethnographers', American Ethnologist 33(4), 499-506

Lee R (1995) Dangerous Fieldwork, Sage, 1995

Liamputtong P and Ezzy D (2005) Qualitative Research Methods, Oxford University Press, 2005

Marks M (2012) 'Ducking and Diving: Ethical and Moral Dilemmas in Doing Criminological Research', Acta Criminologica 25(2), 1-11

Martin R and Kunnen N (2008) 'Reinterpreting the Research Path: Using Qualitative Methods in Homelessness Research' in Maginn PJ, Thompson S and Tonts M (eds) Qualitative Housing Analysis: An International Perspective, Vol 10 Studies in Qualitative Methodology, Emerald Group Publishing Limited, 2008

Miller T and Boulton M (2007) 'Changing Constructions of Informed Consent: Qualitative Research and Complex Social Worlds', Social Science \& Medicine 65, 2199-211

Monaghan LF, O'Dwyer M and Gabe J (2013) 'Seeking University Research Ethics Committee Approval: The Emotional Vicissitudes of a "Rationalised" Process', International Journal of Social Research Methodology 16(1), 65-80

Murphy E and Dingwall R (2007) 'Informed Consent, Anticipatory Regulation and Ethnographic Practice', Social Science \& Medicine 65, 2223-34

Nicholls SG, Brehaut J and Saginur R (2012) 'Social Science and Ethics Review: A Question of Practice not Principle', Research Ethics 8(2), 71-8

NHMRC (2007) Summary of National Statement Content (8 November 2012) $<$ http://www.nhmrc.gov.au/health-ethics/summary-national-statement-content>

Oakes JM (2002) 'Risks and Wrongs in Social Science Research: An Evaluator's Guide to the IRB', Evaluation Research 26(5), 443-79

Parker S and Fopp R (2004) “'I'm the Slice of Pie that's Ostracised ...” Foucault's Technologies, and Personal Agency, in the Voice of Women who are Homeless', Housing, Theory and Society 21(4), $145-54$

Pickering PM (2003) 'Courting Minorities in Postwar Bosnia' in Feldman MS, Bell J and Berger MT (eds) Gaining Access: A Practical and Theoretical Guide for Qualitative Researchers, AltaMira Press, 2003

Putt J (2013) 'Community Studies Using Ethnographic Techniques: Still Relevant to Criminology?', Current Issues in Criminal Justice 25(1), 475 
Schrag ZM (2011) 'The Case against Ethics Review in the Social Sciences', Research Ethics 7(4), $120-31$

Shaw FI (2003) 'Ethics in Qualitative Research and Evaluation', Journal of Social Work 3(1), 9-29

Sieber EJ (1982) The Ethics of Social Research: Survey and Experiments, Springer Verlag, 1982

Smith JV (2009) 'Ethical and Effective Ethnographic Research Methods: A Case Study with Afghan Refugees in California', Journal of Empirical Research on Human Research Ethics 4, 59-72

Spradley JP (1980) Participant Observation, Harcourt Brace Jovanovich College Publishers, 1980

Van den Hoonaard WC (2001) 'Is Research-Ethics Review a Moral Panic?', Canadian Review of Sociology and Anthropology 38(1), 19-36

Wax LM (1980) 'Paradoxes of "Consent" to the Practice of Fieldwork', Social Problems 27(3), 272-83

Westmarland L (2011) Researching Crime and Justice: Tales from the Field, Routledge, 2011 